\title{
Anesthesia for surgical procedures of the morbidly obese
}

\author{
Almıla Gülsün Pamuk, Ayşe Ayyıldız \\ Emergency Surgery Unit, Department of General Surgery, Istanbul University Cerrahpasa Faculty of Medicine, Istanbul, Turkey
}

\begin{abstract}
Surgery for the morbidly obese is no longer a novelty. Understanding the basic mechanisms of the pathophysiology of morbid obesity and taking simple precautions while preparing these patients for surgery will help reduce complications. This review outlined preoperative, perioperative, and postoperative management of the morbidly obese patient in line with the current knowledge. Airway management, drug choices, changes in respiratory, circulatory, urinary, and metabolic systems were discussed. Some early and long-term changes in the morbidly obese, like gastroesophageal reflux and vitamin deficiencies were also summarized to aid in subsequent operations and management.
\end{abstract}

Keywords: Airway; morbid obesity; perioperative management.

\section{Introduction}

Morbid obesity is rapidly increasing in number and causing financial, logistic and public healthcare problems. Morbidly obese individuals get operated on for obesity as well as related and unrelated other surgical problems, making it imperative that all healthcare professionals know how to recognize, classify and treat these patients.

Obesity can be described by different methods involving the weight and height as well as the criteria implicating the fat distribution in the body like skin fold thickness. One of the easiest and universal descriptions is the body mass index (BMI), where BMI $>30$ is considered obese and BMI $>35$ is considered morbidly obese (Table 1). This BMI can be an indication for surgery in the presence of significant comorbidities like diabetes and hyperlipidemia, whereas a BMI $>40$ is by itself an indication for morbid obesity surgery. ${ }^{[1]}$
BMI (body mass index) $=$ weight $(\mathrm{kg}) /$ height squared $\left(\mathrm{m}^{2}\right)$.

\section{Biologic and Physiologic Properties of the Obese Patient}

In the morbidly obese patient, there is an excess accumulation of fat in the neck, airway and omentum as well as the abdomen, hip, waist, bust, legs, and etc. Fat actually weighs less and uses less energy than muscle, bones and other tissues. On the other hand, these people need more oxygen, have a greater challenge in breathing and can easily lose airway patency owing to their net weight. Respiratory resistance is usually high due to the displacement of the diaphragm and reduced lung volumes. This resistance changes chest wall compliance, resulting in a decrease in expiratory reserve volume and a decrease in 
Table 1. Normal and overweight patients with the corresponding body mass index (BMI)
Underweight

Normal

Overweight

Obese

Superobese
$\mathrm{BMI}<18.5$

$18.5<\mathrm{BMI}<24.9$

$25<\mathrm{BMI}<29.9$

Class $130<\mathrm{BMl}<34.9$

Class $235<\mathrm{BMI}<39.9$

Class $340<\mathrm{BMI}<49.9$

$\mathrm{BMI}>50$ functional residual capacity. These physiologic changes in obese individuals shortens the apnea time to desaturation during anesthesia induction. ${ }^{[2]}$

Tidal volume and total lung capacity decrease and may lead to the development of obesity hypoventilation syndrome. ${ }^{[3]}$ In Obesity Hypoventilation Syndrome (Pickwickian Syndrome), chronic hypercapnia and hypoxia accompanies hypoventilation and patients suffer from hypersomnolence. In time, policytemia and right ventricular failure complicate the problem further. The right to left shunt, causing right ventricular failure and pulmonary hypertension, is a bad prognostic criterion for anesthesia induction. ${ }^{[3,4]}$ Supine position and obstructive sleep apnea intensify these symptoms. ${ }^{[5,6]}$ Obesity causes small airway collapse as well aschronic inflammation, and Interleukin- 6 and Cyclooxygenase- 2 released from fatty tissue have also been implicated in the development of accompanying asthma in obesity. ${ }^{[7]}$

As the need for oxygen increases, total blood volume and stroke volume also increase. The stroke volume, in turn, increases the consumption of oxygen especially important in the obese patient. The increase in stroke volume increases end-diastolic volume and pressure, and an eccantric ventricular hyperthropy develops. Mean arterial pressures usually do not change until hypertension develops. Hypertension increases systemic ventricular resistance and causes concentric hyperthropy. Both types of hyperthropy may lead to heart failure. ${ }^{[8]}$

One of the major problems accompanying obesity is the metabolic syndrome which introduces three important risk factors: dyslipidemia, hypertension and hyperglycemia (Table 2). Metabolic syndrome increases heart disease risk twofold and type 2 diabetes risk fivefold. ${ }^{[9]}$

Current obesity research focuses on pathophysiologic mediators. Leptin resistance seems to develop as omental fat increases. Interleukin- 6 secreted by adiposites and fatty tissue macrophages play important roles in the development of atherosclerosis and arterial wall changes in chronic inflammation. It is also procoagulant by increasing platelet number and activity as well as fibrinogen. ${ }^{[10]}$

Morbid obesity is a serious health problem effecting the simplest daily activities like walking and breathing, and may trigger conditions such as gastrooesefagial reflux, bile calculi, ostheoarthritis, disc hernias, stres incontinance, infertility, depression, and many cancer types like oesefagial, endometrial, breast, colorectal and renal cancer.

\section{Preoperative Preparation of the Morbidly Obese Patient}

All morbidly obese patients are evaluated by a council for their metabolic, endocrinologic, cardiac, respiratory as well as psychological status before they are thought eligible for the operation. These evaluations are always very useful for the anesthesia team; however, not always enough. Although the severity of the obesity does not always correlate well with the airway patency, all morbidly obese patients should be prepared and treated like potential difficult airways. Many articles suggest that a neck circumference greater than $44 \mathrm{~cm}$ and presence of sleep apnea are important indicators while others find Mallampati scores and male gender to be more important. ${ }^{[1]]}$ Obesity, advanced age, toothless, bearded individiuals with increased chest circumference and sleep apnea are also difficult to ventilate through mask and airway. Successful

Table 2. Components of metabolic syndrome

\begin{tabular}{lcc} 
Dyslipidemia & Triglyceride $>$ & $\mathrm{HDL}<50 \mathrm{mg} / \mathrm{dL}$ women, \\
& $150 \mathrm{mg} / \mathrm{dL}$ & $\mathrm{HDL}<40 \mathrm{mg} / \mathrm{dL}$ men \\
Hypertension & Systolic BP $>$ & Diastolic BP $>85 \mathrm{mmHg}$ \\
& $130 \mathrm{mmHg}$ & \\
Fasting glucose & $\mathrm{Glc}>110 \mathrm{mg} / \mathrm{dL}$ & Insulin resistance \\
Abdominal circumference & $>100 \mathrm{~cm} \mathrm{men}$ & $>87.5 \mathrm{~cm}$ women \\
\hline
\end{tabular}


intubations using C-trach and Airtraq devices, awake fiberoptic, Glidescope in thesemi-sitting (semi-fowler) patients have been performed. ${ }^{[12-14]}$ Head and neck positions are especially important and sniff and ramp positions should be maintained throughout the operation. ${ }^{[15-18]}$ Patients with obesity hypoventilation syndrome should be evaluated with arterial blood gases, respiratory function tests, and echocardiography as needed, and postoperative CPAP use should be discussed if necessary.

Morbid obesity is not correlated with the severity of gastroeosefagial reflux (GERD) or increase in aspiration risk in the preoperative period. Therefore, the ASA 2011 guidelines do not suggest the routine use of preoperative nausea prophylaxis. ${ }^{[19]}$ Preoperative anxiolytics and sedatives must be avoided in the morbidly obese, and airway reflexes and patient cooperation should be maintained as long as possible. Although for some recent literature that suggests atelectasis and shunting caused by it, preoxygenation has been advocated for the morbidly obese group of patients. ${ }^{[20,21]}$ Cardiac function should be evaluated for the presence of hypertension, cardiomyopathies, arrhythmias, and ischemic heart disease as well as venous stasis and peroperative pulmonary emboli risks. These patients also need to be evaluated and prophylactic treatments should be started for reflux, aspiration,metabolic syndrome and glucose control. It should be kept in mind that some of the procedures (i.e. gastric banding) increase reflux incidence even a long time after treatment and even after weight loss. ${ }^{[2]}$

\section{Intraoperative Management of the Morbidly Obese Patient}

Although special surgical tables and transfer systems are available, a large number of morbidly obese patients are operated on normal operating tables with a weight limit of $200 \mathrm{~kg}$. The main challenge is to protect patients' position and pressure points where the rolls and padding designed for normal weight patients may be inadequate. Rabdomyolisis due to immobilization has been a major problem in this patient group and minimizing surgical procedure time seems to be the only viable solution as the sex (male) and BMI of patients cannot be changed. ${ }^{[23]}$

A team of multiple anesthetists should be present for the induction and a difficult airway kit should be readily available. As anesthesiologists throughout the world have gained experience with this subgoup of patients, fewer airway catastrophes are being reported and securing the airway has become more of a routine. ${ }^{[2]}$ Our own experience parallels those of the reports in that we reserve awake fiberoptic intubation for the super morbidly obese male patients with obstructive sleep apnea or accompanying diseases like advanced ankylosing spondilitis. For all other patients, head up positions with video laryngoscopic techniques seem to be the fastest and safest although many patients' airways could be secured with indirect laryngoscopy alone.

Lung protective ventilation strategies including low tidal volume, PEEP $\left(10-15 \mathrm{cmH}_{2} \mathrm{O}\right.$ following recruitment maneuver), RM (6-20 sec. long with plateu pressures of $\left.40-55 \mathrm{cmH}_{2} \mathrm{O}\right)$ and relatively lower oxygen values $\left(\mathrm{FiO}_{2}\right.$ $\% 0.5-0.8$ to prevent atelectasis and oxygen toxicity) as well asnormocarbia-adjusted ventilation values and keeping the patient in the head-up position are recommended. ${ }^{[7,22]}$ As nasogastric tubes and bougies, dilators etc. may be used and repositioned several times during the operation, securing the airway tubes and the follow-up of secretions and bleeding are important. It is imperative that timely premedication concerning pharyngeal secretions, reflux etc. is done. Ultrasonographic guidance is recommended for the placement of arterial or central lines. Invasive monitorization of arterial pressures, central venous pressures and transeosefagial echocardiography may be used in selected patients. ${ }^{[8]}$ If the blood pressure is going to be monitored, non-invasive special arm pressure cuffs for the obese must be used or normal adult cuffs can be placed on the forearm or leg.

Drug doses calculated based on lean body mass usually proves insufficient. ${ }^{[25]}$ Blood volume is increased as well as cardiac output and water soluble drugs are distributed fast. Fat soluble drugs are also quickly redistributed; hence, using real body weight at least for the first doses might be prudent. Drugs like propofol have been found to be sufficiently eliminated so total body weight is more predictive than lean body or ideal body weight. ${ }^{[26]}$ On the other hand, ideal body weight might be used for opioid drug doses. Muscle relaxants have also been dosed using ideal body weight; hovewer, recent publications using sugammadex for muscle relaxant reversal show that even doses for total body weight can be used without prolonging the procedure. ${ }^{[27]}$ Due to these controversies of intravenous dosing, some authors suggest that using inhalational anesthesia results in faster awakening. ${ }^{[28]}$ If total intravenous anesthesia is to be chosen, continuous monitorization with BIS (bispectral index) and using TCI (target controlled infusion) might be an option. One 
such BIS-monitored study has found MAC of sevoflurane in obese patients to be greater than non-obese adults. ${ }^{[29]}$ Since morbidly obese patients have greater amount of epidural fat, epidural anesthesia with the same amount of drugs might show greater distribution to upper dermatomes.

Many surgical procedures, including obesity surgery, are moving towards laparascopic techniques which minimizes the postoperative pain and infection, as well as surgical site complications (Table 3). However, there is also a risk for having difficulty in optimizing viewing qualities with the morbidly obese and intraabdominal pressures might be slightly increased. Pneumoperitoneum causes intraabdominal pressures to rise, increasing the atelectatic areas while the need for increased carbondioxide elimination calls for longer expiratory periods. Although one recent study has shown optimized mechanics and oxygenation, a large series has not been used or very obese patients have not been included, and thus larger studies are needed. ${ }^{[26]}$ Several modalities have been used to prolong the safe duration of apnea. ${ }^{[27]}$ Another study has revealed that single lung ventilation in the morbidly obese is also possible if surgical and anesthesia teams work together and provide oxygenation breaks as needed. ${ }^{[28]}$

Since fat tissue increases much more than lean tissue, morbidly obese individuals are relatively hypovolemic and anesthesia induction with acute vasodilation may cause acute or serious hypotension. On the other hand, large fluid overloads may worsen lung mechanics and more hypertensive episodes may be seen in the postoperative period, so controlled hydration must be recommended. ${ }^{[29]}$ Urine output also decreases during pneumoperitoneum; however, as long as intraabdominal pressures are below $15 \mathrm{mmHg}$, not improving oxygenation, it will effect both reflected pressures and urine output. ${ }^{[30]}$

It should be remembered that perioperative (especially, the immediate preoperative) period is not the ideal time to restrict calorie intakes of the morbidly obese patients. Patients in metabolic syndrome may have abnormal re-

Table 3. Bariatric procedures

Restrictive procedures

Malabsorbtive procedures
Gastric banding

Sleeve gastrectomy

Biliopancreatic diversion

Duodenal switch

Roux-en-Y gastric bypass sponse to fasting and operative stress. Continuous blood sugar controls may be needed in this period..$^{[9]}$

\section{Postoperative Management of the Morbidly Obese Patient}

As morbidly obese patients awake from inhalational anesthesia, several redistribution periods and fluctuations of consciousness may be seen. Intravenous anesthetic doses are still a subject of controversy. While recent studies advocate larger doses to be used, cumulative effects of even smaller doses may impair awakening. ${ }^{[31]}$ As these fluctuations in consciousness may cause hypoventilation and positional atelectatic areas in the lungs impair oxygenation, these patients should be under monitorized carefor longer periods of time. Many new studies show that a six hour PACU stay may be acceptable and over-the-night ICU stays should be reserved for select patients. ${ }^{[24]}$ Pulmonary physiotherapy and encouraging patients to cough minimizes pulmonary complications. ${ }^{[18]}$ Patients using CPAP devices before the operation should be encouraged to bring their own devices and use them in the ward or PACU. Patients with atelectatic areas might also require BI-PAP support. Usually, awakening in the semi-erect position improves ventilatory mechanics as well as minimizing the risk for regurgitation and aspiration. ${ }^{[16]}$

Pain control after morbid obesity surgery is not predominantly done with opioids. Many adjuvant therapies have been proposed like local anesthetic infiltration at the insertion sites and bilateral TAP (Transversus Abdominis Plane) blocks. ${ }^{[32]}$ Most popular multimodal therapies involve local anesthetic infiltration at insertion site and potent non-steroidal anti-inflammatory drugs like ketorolac. ${ }^{[33-35]}$ Paracetamol, which has also been found to diminish postoperative nausea, can also be used in combination. ${ }^{[36]}$ Alpha 2 agonists like clonidine and dexmedetomidine have also been used to diminish opioid use, as well as antiemetics, and shorten PACU stay. ${ }^{[37-40]}$ Some ongoing studies propose the use of ketamine and antiepileptics like pregabaline and gabapentine. Pain control through an epidural catheter may also be proposed, any antiaggregant drug use should be taken into consideration. Landmarks are hard to find so ultrasound guidance would be prudent. ${ }^{[40]}$ Special long needles produced specially for morbidly obese patients should be used and cephalad drug distribution should be remembered.

This patient group has a predisposition towards venous stasis and if postoperative mobilization is delayed, pro- 
tective compressive techniques and low molecular weight heparin should be considered. ${ }^{[4]}$ Early mobilization, eliminating catheters, and correct dosing of antibiotic regimens would also minimize postoperative infection risks.

Long surgeries and late mobilization have been shown to increase risk of rabdomyolisis, further decreasing the percentage of muscle tissue, making postoperative mobilization even harder, and also complicating ventilation and impairing renal function. ${ }^{[23]}$ Postoperative urine output should be monitorized and normalized.

\section{Issues Concerning Patients with Past History of Obesity Surgery}

Patients undergoing morbid obesity surgery may encounter several early and late complications and problems. ${ }^{[42]}$ Early surgical problems may be bleeding (rupture of liver, spleen or blood vessels), intestinal obstructions, cardiac problems, deep venous thrombosis, intestinal dehiscense or rupture, gastrointestinal dysfunction, followed by surgical site infections, hernias, leakage of intestinal content, marginal ulcers in the gastric pouch, ventilatory problems, pneumonia, fluid overload, stenosis, and reversible hair thinning/alopesia. Sometimes additional operations and anesthesia may be needed to correct some of these problems.

Some other changes caused by surgery are expected to be permanent and require long-term or life-time adaptations. One of these is change in bowel movement and dyspepsia. Since intestinal absorption may be impaired, some vitamin and mineral deficiencies such as iron deficiency, folate deficiency, vitamin B deficiencies (predominantly, B1 and B12), copper, chrome and vitamin D deficiency may be seen. ${ }^{[43]}$ GERD is seen especially in gastric band patients and may be even more prominent postoperatively. ${ }^{[44]}$ Bile calculi are also seen more often after weight loss.

\section{Conclusion}

Morbid obesity is a health risk often requiring surgery. As anesthesiologists gain more experience with this patient group and adapt to new surgical techniques, anesthetizing morbidly obese patients becomes easier. Nevertheless, it should always be kept in mind that these patients have many characteristic problems such as difficult airway, difficulty in positioning, decreased urinary output, rabdomyolisis, and cardiac problems. While some of these problems like metabolic syndrome and obstructive sleep apnea may diminish after surgery and accompanying weight loss, other problems like mineral deficiencies and GERD might be triggeredor worsened. Anesthesiologists and surgeons can best defeat these problems by awareness and teamwork.

\section{References}

1. Miller RD. Anesthesia for Bariatric Surgery. Miller's Anesthesia. 7th ed. Ch 64; 2009.

2. Damia G, Mascheroni D, Croci M, Tarenzi L. Perioperative changes in functional residual capacity in morbidly obese patients. Br J Anaesth 1988;60:574-8.

3. Lin CC, Wu KM, Chou CS, Liaw SF. Oral airway resistance during wakefulness in eucapnic and hypercapnic sleep apnea syndrome. Respir Physiol Neurobiol 2004;139:215-24.

4. Söderberg $M$, Thomson $D$, White $T$. Respiration, circulation and anaesthetic management in obesity. Investigation before and after jejunoileal bypass. Acta Anaesthesiol Scand 1977;21:55-61.

5. Lee MY, Lin CC, Shen SY, Chiu CH, Liaw SF. Work of breathing in eucapnic and hypercapnic sleep apnea syndrome. Respiration 2009;77:146-53.

6. Jense HG, Dubin SA, Silverstein PI, O'Leary-Escolas U. Effect of obesity on safe duration of apnea in anesthetized humans. Anesth Analg 1991;72:89-93.

7. Aldenkortt $M$, Lysakowski $C$, Elia $N$, Brochard L, Tramèr MR. Ventilation strategies in obese patients undergoing surgery: a quantitative systematic review and meta-analysis. $\mathrm{Br} \mathrm{J}$ Anaesth 2012;109:493-502.

8. Domi R, Laho H. Anesthetic challenges in the obese patient. J Anesth 2012;26:758-65.

9. Neligan PJ. Metabolic syndrome: anesthesia for morbid obesity. Curr Opin Anaesthesiol 2010;23:375-83.

10. Alam I, Lewis K, Stephens JW, Baxter JN. Obesity, metabolic syndrome and sleep apnoea: all pro-inflammatory states. Obes Rev 2007;8:119-27.

11. Neligan PJ, Porter S, Max B, Malhotra G, Greenblatt EP, Ochroch EA. Obstructive sleep apnea is not a risk factor for difficult intubation in morbidly obese patients. Anesth Analg 2009;109:1182-6.

12. Gupta D, Rusin K. Videolaryngoscopic endotracheal intubation (GlideScope) of morbidly obese patients in semi-erect position: a comparison with rapid sequence induction in supine position. Middle East J Anaesthesiol 2012;21:843-50.

13. Weingarten TN, Hawkins NM, Beam WB, Brandt HA, Koepp DJ, Kellogg TA, et al. Factors associated with prolonged anesthesia recovery following laparoscopic bariatric surgery: a retrospective analysis. Obes Surg 2015;25:1024-30.

14. De Jarnett $D$. Use of a positive pressure endoscopic mask to assist with positive pressure ventilation in a morbidly obese patient during fiberoptic intubation: a case report. AANA J 2013;81:282-4.

15. Dhonneur G, Abdi W, Ndoko SK, Amathieu R, Risk N, El Housseini $L$, et al. Video-assisted versus conventional tra- 
cheal intubation in morbidly obese patients. Obes Surg 2009;19:1096-101.

16. Collins JS, Lemmens HJ, Brodsky JB, Brock-Utne JG, Levitan RM. Laryngoscopy and morbid obesity: a comparison of the "sniff" and "ramped" positions. Obes Surg 2004;14:1171-5.

17. El-Orbany M, Woehlck H, Salem MR. Head and neck position for direct laryngoscopy. Anesth Analg 2011;113:103-9.

18. Thomas JA, Mclntosh JM. Are incentive spirometry, intermittent positive pressure breathing, and deep breathing exercises effective in the prevention of postoperative pulmonary complications after upper abdominal surgery? A systematic overview and meta-analysis. Phys Ther 1994;74:3-10.

19. American Society of Anesthesiologists Committee. Practice guidelines for preoperative fasting and the use of pharmacologic agents to reduce the risk of pulmonary aspiration: application to healthy patients undergoing elective procedures: an updated report by the American Society of Anesthesiologists Committee on Standards and Practice Parameters. Anesthesiology 2011;114:495-511.

20. Dixon BJ, Dixon JB, Carden JR, Burn AJ, Schachter LM, Playfair JM, et al. Preoxygenation is more effective in the 25 degrees head-up position than in the supine position in severely obese patients: a randomized controlled study. Anesthesiology 2005;102:1110-5.

21. Pandit JJ, Duncan T, Robbins PA. Total oxygen uptake with two maximal breathing techniques and the tidal volume breathing technique: a physiologic study of preoxygenation. Anesthesiology 2003;99:841-6.

22. Koolwijk J, Schors M, el Bouazati S, Noordergraaf GJ. Airway management concerns in patient with gastric banding procedures. BMJ Case Rep 2013. pii: bcr2013201009.

23. Chakravartty S, Sarma DR, Patel AG. Rhabdomyolysis in bariatric surgery: a systematic review. Obes Surg 2013;23:1333-40.

24. de la Matta-Martín M, Acosta-Martínez J, Sánchez-Carrillo F. Anesthesia for bariatric surgery: 8-year retrospective study: are our patients now easier to manage? Rev Esp Anestesiol Reanim 2014;61:422-8.

25. Hanley MJ, Abernethy DR, Greenblatt DJ. Effect of obesity on the pharmacokinetics of drugs in humans. Clin Pharmacokinet 2010;49:71-87.

26. Salihoglu T, Salihoglu Z, Zengin AK, Taskin M, Colakoglu N, Babazade $R$. The impacts of super obesity versus morbid obesity on respiratory mechanics and simple hemodynamic parameters during bariatric surgery. Obes Surg 2013;23:379-83.

27. Carron M, Veronese S, Foletto M, Ori C. Sugammadex allows fast-track bariatric surgery. Obes Surg 2013;23:1558-63.

28. Futier E, Constantin JM, Paugam-Burtz C, Pascal J, Eurin M, Neuschwander A, et al; IMPROVE Study Group. A trial of intraoperative low-tidal-volume ventilation in abdominal surgery. N Engl J Med 2013;369:428-37.

29. Zeidan A, Mazoit JX. Minimal alveolar concentration of sevoflurane for maintaining bispectral index below 50 in morbidly obese patients. Acta Anaesthesiol Scand 2013;57:474-9.

30. Sharma SK, McCauley J, Cottam D, Mattar SG, Holover S, Dallal $\mathrm{R}$, et al. Acute changes in renal function after laparo- scopic gastric surgery for morbid obesity. Surg Obes Relat Dis 2006;2:389-92.

31. Diepstraten J, Chidambaran V, Sadhasivam S, Esslinger HR, Cox SL, Inge TH, et al. Propofol clearance in morbidly obese children and adolescents: influence of age and body size. Clin Pharmacokinet 2012;51:543-51.

32. Albrecht E, Kirkham KR, Endersby RV, Chan VW, Jackson T, Okrainec A, et al. Ultrasound-guided transversus abdominis plane (TAP) block for laparoscopic gastric-bypass surgery: a prospective randomized controlled double-blinded trial. Obes Surg 2013;23:1309-14.

33. Govindarajan R, Ghosh B, Sathyamoorthy MK, Kodali NS, Raza A, Aronsohn J, et al. Efficacy of ketorolac in lieu of narcotics in the operative management of laparoscopic surgery for morbid obesity. Surg Obes Relat Dis 2005;1:530-5.

34. Kamelgard JI, Kim KA, Atlas G. Combined preemptive and preventive analgesia in morbidly obese patients undergoing open gastric bypass: A pilot study. Surg Obes Relat Dis 2005;1:12-6.

35. Schumann R, Shikora S, Weiss JM, Wurm H, Strassels S, Carr DB. A comparison of multimodal perioperative analgesia to epidural pain management after gastric bypass surgery. Anesth Analg 2003;96:469-74.

36. Apfel CC, Turan A, Souza K, Pergolizzi J, Hornuss C. Intravenous acetaminophen reduces postoperative nausea and vomiting: a systematic review and meta-analysis. Pain 2013;154:677-89.

37. Pawlik MT, Hansen E, Waldhauser D, Selig C, Kuehnel TS. Clonidine premedication in patients with sleep apnea syndrome: a randomized, double-blind, placebo-controlled study. Anesth Analg. 2005;101:1374-80.

38. Feld JM, Hoffman WE, Stechert MM, Hoffman IW, Ananda RC. Fentanyl or dexmedetomidine combined with desflurane for bariatric surgery. J Clin Anesth 2006;18:24-8.

39. Tufanogullari B, White PF, Peixoto MP, Kianpour D, Lacour T, Griffin J, et al. Dexmedetomidine infusion during laparoscopic bariatric surgery: the effect on recovery outcome variables. Anesth Analg 2008;106:1741-8.

40. Bakhamees HS, El-Halafawy YM, El-Kerdawy HM, Gouda NM, Altemyatt S. Effects of dexmedetomidine in morbidly obese patients undergoing laparoscopic gastric bypass. Middle East J Anaesthesiol 2007;19:537-51.

41. Imberti D, Baldini E, Pierfranceschi MG, Nicolini A, Cartelli C, De Paoli $\mathrm{M}$, et al. Prophylaxis of venous thromboembolism with low molecular weight heparin in bariatric surgery: a prospective, randomised pilot study evaluating two doses of parnaparin (BAFLUX Study). Obes Surg 2014;24:284-91.

42. Podnos YD, Jimenez JC, Wilson SE, Stevens CM, Nguyen NT. Complications after laparoscopic gastric bypass: a review of 3464 cases. Arch Surg 2003;138:957-61.

43. Malinowski SS. Nutritional and metabolic complications of bariatric surgery. Am J Med Sci 2006;331:219-25.

44. DuPree CE, Blair K, Steele SR, Martin MJ. Laparoscopic sleeve gastrectomy in patients with preexisting gastroesophageal reflux disease : a national analysis. JAMA Surg 2014;149:328-34. 